\title{
Trauma Surgery $\&$ Acute Care Open \\ Trauma and acute care surgeons report prescribing less opioids over time
}

\author{
Jamie E Anderson, ${ }^{\oplus}$ Christine S. Cocanour, Joseph M Galante
}

Department of Surgery, University of California, Davis, Sacramento, California, USA

\section{Correspondence to} Dr Jamie E Anderson, Department of Surgery, University of California, Sacramento, CA 95817, USA; jeanderson@ucdavis.edu

Presented as an Oral Presentation at the 4th Annual World Trauma Congress, San Diego, CA, on September 27 2018.

Received 4 October 2018 Revised 2 January 2019 Accepted 24 January 2019 (c) Author(s) (or their employer(s)) 2019. Re-use permitted under CC BY-NC. No commercial re-use. See rights and permissions. Published by BMJ.

To cite: Anderson JE, Cocanour CS, Galante JM. Trauma Surg Acute Care Open 2019:4:e000255.

\section{ABSTRACT}

Introduction Confronted with the opioid epidemic, surgeons must play a larger role to reduce risk of opioid abuse while managing acute pain. Having a better understanding of the beliefs and practices of trauma and acute care surgeons regarding discharge pain management may offer potential targets for interventions beyond fixed legal mandates. Methods An Institutional Review Board-approved electronic survey was sent to trauma and acute care surgeons who are members of the American Association for the Surgery of Trauma, and trauma and acute care surgeons and nurse practitioners at a Level 1 trauma center in February 2018. The survey included four case-based scenarios and questions about discharge prescription practices and beliefs.

Results of 66 respondents, most (88.1\%) were at academic institutions. Mean number of opioid tablets prescribed was 20-30 (range 5-90), with the fewest tablets prescribed for elective laparoscopic cholecystectomy and the most for rib fractures. Few prescribed both opioid and non-opioid medications ( $22.4 \%$ to $31.4 \%$ ). Most would not change the number/ strength of medications $(69.2 \%)$, dose $(53.9 \%)$, or number of tablets of opioids (83.1\%) prescribed if patients used opioids regularly prior to their operation. The most common factors that made providers more likely to prescribe opioids were high inpatient opioid use $(32.4 \%)$, history of opioid use/abuse $(24.5 \%)$, and if the patient lives far from the hospital (12.9\%). Most providers in practice $>5$ years reported a decrease in opioids $(71.9 \%)$ prescribed at discharge.

Conclusion Trauma and acute care surgeons and nurse practitioners reported decreasing the number/amount of opioids prescribed over time. Patients with high opioid use in the hospital, history of opioid use/abuse, or who live far from the provider may be prescribed more opioids at discharge.

Level of evidence Level IV.

\section{BACKGROUND}

Deaths due to drug overdoses remain a leading cause of preventable adult death in the USA, contributing to almost 64000 deaths in 2016. Opioids, both illicit and prescription medications, are the main driver of drug overdose deaths, contributing to over $66 \%$ of deaths in $2016 .{ }^{1}$ Although there has been a decrease in annual opioid-prescribing rates since 2012, 17\% of Americans still had at least one opioid prescription filled in 2017. ${ }^{2}$ Of those, an average of 3.4 opioid prescriptions were dispensed per patient. ${ }^{2}$
Several studies have suggested surgical patients undergoing both elective and emergent operations are at high risk for developing opioid dependence. Of over 36000 patients who underwent an operation, Brummett et al demonstrated that patients had an increased risk of persistent opioid use at $5.9 \%$ to $6.5 \%$ (even after minor operations) compared with $0.4 \%$ in non-surgical patients. ${ }^{3}$ Jiang et al calculated the prevalence of chronic opioid use at 90 days after operation at 9.2\% among 79000 patients, with highest rates among orthopedic, neurosurgery, and gastrointestinal surgery patients. ${ }^{4}$ Among nearly 642 000 opioid-naïve non-trauma surgical patients, Sun et al calculated the 1 year postoperative incidence of chronic opioid use at $0.2 \%$ to $1.4 \%$, compared with $0.1 \%$ in non-surgical patients. ${ }^{5}$ Among a sample of 1.3 million opioid-naïve commercially insured patients (both surgical and non-surgical) from 2006 to $2015,70 \%$ of patients had an initial duration of opioids of less than 1 week, but $6.0 \%$ had continued opioid use at 1 year and $1.9 \%$ had continued opioid use at 3 years. ${ }^{6}$

Confronted with the opioid epidemic, surgeons must play a more active role to reduce risk of opioid abuse while ensuring adequate management of acute pain. This study surveys trauma and acute care surgeons and nurse practitioners about their postoperative pain prescription practices. Having a better understanding of the beliefs and practices of trauma and acute care surgeons regarding discharge pain management may offer potential targets for nuanced interventions beyond fixed legal mandates.

\section{METHODS}

A 30-question electronic survey was created by the authors and refined after testing several iterations among faculty surgeons and surgical residents in this Department of General Surgery. The survey asked questions based predominantly on how providers would prescribe pain medications at time of discharge for patients in four clinical scenarios: a 40-year-old woman who underwent an elective, outpatient laparoscopic cholecystectomy; a 50 -year-old man who was postoperative day 6 from an emergent, open sigmoidectomy for diverticulitis; a 40-year-old man who was postoperative day 5 from a negative trauma exploratory laparotomy; and a 30-year-old man who was postinjury day 1 from a motorcycle collision with four unilateral non-displaced rib fractures. Additional questions were asked regarding practice patterns and beliefs about pain and pain management.

The survey was sent electronically via Survey Gizmo to all members of the American Association for the Surgery of Trauma (AAST) after approval by 


\begin{tabular}{lc}
\hline Table 1 Survey participants & Total=66 \\
\hline & \\
\hline Gender, $\mathrm{n}(\%)$ & $17(25.8)$ \\
\hline Female & $48(72.7)$ \\
\hline Male & $1(1.5)$ \\
\hline Other/prefer not to state & \\
\hline Provider type, $\mathrm{n}(\%)$ & $61(92.4)$ \\
\hline Surgeon & $5(7.6)$ \\
\hline Nurse practitioner & \\
\hline Years in practice, $\mathrm{n}(\%)$ & $2(3.0)$ \\
\hline$<5$ & $11(16.7)$ \\
\hline $5-9$ & $12(18.2$ \\
\hline $10-14$ & $9(13.6)$ \\
\hline $15-19$ & $8(12.1)$ \\
\hline $20-24$ & $8(12.1)$ \\
\hline $25-29$ & $16(24.2)$ \\
\hline $30+$ & \\
\hline Type of practice, $\mathrm{n}(\%)$ & $58(87.9)$ \\
\hline Academic & $8(12.1)$ \\
\hline Private/community & \\
\hline
\end{tabular}

the organization. The survey was sent via email a total of three times and the survey period was open for 4 weeks during the month of February 2018. The survey was also sent directly to all trauma and acute care surgeons and nurse practitioners at a single Level 1 trauma center.

\section{RESULTS}

Sixty-six trauma and acute care surgeons and nurse practitioners from 24 states responded, including $33(50 \%)$ from California. Most were surgeons (92.4\%), male (72.7\%), and in academic practices $(87.9 \%$; table 1$)$. There was a range of experience, including $24.2 \%$ with over 30 years of practice.

Seventy-four to eighty-six percent of providers prescribed opioids to patients in each of the four scenarios (table 2). Sixtyseven to seventy-seven percent of providers who prescribed opioids only prescribed opioids and did not include any additional non-opioid medications to patients in each of these four scenarios. The mean number of opioid tablets prescribed was 20 for patients who underwent laparoscopic cholecystectomy (range 3-40) and 30 for all other scenarios (range 10-90). Mean number of refills was 0 (range $0-2$ ).

Twenty-three to thirty percent of providers prescribed non-opioid pain medication (acetaminophen, ibuprofen, or other non-steroidal anti-inflammatory drugs) to patients in each of the four scenarios, with $10 \%$ to $13 \%$ of these prescribing only non-opioid pain medications. The mean number of non-opioid tablets prescribed was higher (mean 30-48, range 7-90) although the mean number of refills was still 0 (range $0-3$ ).

Providers expect patients undergoing elective laparoscopic cholecystectomy to have the shortest duration of postoperative acute pain that would best be managed with opioid pain medications $(67.7 \%$ responded $0-3$ days, whereas $30.8 \%$ responded 4-7 days; table 3). Providers expected patients undergoing emergent sigmoidectomy and negative exploratory laparotomy to have a longer duration of acute pain ( $45.3 \%$ to $46.2 \%$ between 8 and 14 days and $39.1 \%$ to $43.1 \%$ between 15 and 21 days), and the longest duration and widest range among patients with four unilateral rib fractures $(24.7 \%$ between 0 and 7 days; $44.6 \%$ between 8 and 14 days; $26.2 \%$ between 15 and 30 days; and $4.6 \%$ greater than 30 days).

Among patients undergoing elective outpatient laparoscopic cholecystectomy, we asked how provider prescription practices would change if their patients were using opioid pain medications regularly prior to their operation. Most responded they would not change the number/strength, dose, or number of tablets of opioid medications (53.9\% to 83.1\%) and non-opioid medications $(55.0 \%$ to $69.6 \%$; table 4$)$.

Providers were asked to choose three factors that made them more likely to prescribe more opioid tablets (or a higher dose of opioids) and three factors that made them more likely to prescribe less opioid tablets (or a lower dose of opioids; table 5). The top three reasons providers were more likely to prescribe more opioids were: high use in the hospital (32.4\%), history of opioid use/abuse (24.5\%), and if the patient lives far away $(12.9 \%)$. The top three reasons providers were more likely to prescribe less opioids were: patient frailty $(24.4 \%)$, older patients $(23.3 \%)$, and low body mass index $(7.6 \%)$ and history of drug/alcohol abuse (7.6\%).

Providers always (43.9\%) or often (34.9\%) ask patients about their previous experience with opioids (table 6). However, providers less often create pain contracts with patients (sometimes $21.2 \%$, rarely $57.6 \%$, and never $15.2 \%$ ). Providers variably use a prescription history database (such as the CURES

Table 2 Number of opioids and non-opioid pain medications typically prescribed at time of discharge after each clinical scenario

\begin{tabular}{|c|c|c|c|c|c|}
\hline & & $\begin{array}{l}\text { Elective } \\
\text { laparoscopic } \\
\text { cholecystectomy }\end{array}$ & $\begin{array}{l}\text { Emergent } \\
\text { sigmoidectomy }\end{array}$ & $\begin{array}{l}\text { Negative } \\
\text { exploratory } \\
\text { laparotomy }\end{array}$ & $\begin{array}{l}\text { Four } \\
\text { unilateral rib } \\
\text { fractures }\end{array}$ \\
\hline \multirow[t]{4}{*}{ Opioids } & Number of providers who prescribed opioids (\%) & $56(84.8)$ & $49(74.2)$ & $55(83.3)$ & $57(86.4)$ \\
\hline & $\begin{array}{l}\text { Number of providers who prescribed only opioids (\% among } \\
\text { those who prescribed opioids) }\end{array}$ & $43(76.8)$ & $33(67.3)$ & $41(74.5)$ & $39(68.4)$ \\
\hline & Number of tabs prescribed, mean (range) & $20(3-40)$ & $30(10-60)$ & $30(10-60)$ & $30(5-90)$ \\
\hline & Number of refills, mean (range) & $0(0-1)$ & $0(0-1)$ & $0(0-1)$ & $0(0-2)$ \\
\hline \multirow[t]{4}{*}{ Non-opioids } & Number of providers who prescribed non-opioids (\%) & $15(22.7)$ & $18(27.3)$ & $16(24.2)$ & $20(30.3)$ \\
\hline & $\begin{array}{l}\text { Number of providers who prescribed only non-opioids (\% among } \\
\text { those who prescribed non-opioids) }\end{array}$ & $2(13.3)$ & $2(11.1)$ & $2(12.5)$ & $2(10.0)$ \\
\hline & Number of tablets prescribed, mean (range) & $30(10-60)$ & $35(7-90)$ & $42.5(20-90)$ & $47.5(21-90)$ \\
\hline & Number of refills, mean (range) & $0(0-3)$ & $0(0-3)$ & $0(0-3)$ & $0(0-3)$ \\
\hline Both & $\begin{array}{l}\text { Number of providers who prescribed both opioids and non- } \\
\text { opioids (\%) }\end{array}$ & $13(22.4)$ & $16(31.4)$ & $14(24.6)$ & $18(30.5)$ \\
\hline
\end{tabular}


Table 3 Anticipated length of postoperative acute pain that would best be managed with opioids ( $\mathrm{n}=$ total number of respondents)

\begin{tabular}{|c|c|c|c|c|}
\hline & $\begin{array}{l}\text { Elective laparoscopic } \\
\text { cholecystectomy }(n=65)\end{array}$ & $\begin{array}{l}\text { Emergent sigmoidectomy } \\
(\mathrm{n}=65)\end{array}$ & $\begin{array}{l}\text { Negative exploratory } \\
\text { laparotomy }(n=64)\end{array}$ & $\begin{array}{l}\text { Four unilateral rib fractures } \\
(n=55)\end{array}$ \\
\hline $0-3$ days, $\mathrm{n}(\%)$ & $44(67.7)$ & $2(3.1)$ & $8(12.5)$ & $7(10.8)$ \\
\hline 4-7 days, n (\%) & $20(30.8)$ & $5(7.7)$ & $2(3.1)$ & $9(13.9)$ \\
\hline 8-14 days, n (\%) & $1(1.5)$ & $30(46.2)$ & $29(45.3)$ & $29(44.6)$ \\
\hline 15-21 days, n (\%) & $0(0)$ & $28(43.1)$ & $25(39.1)$ & $2(18.5)$ \\
\hline 22-30 days, n (\%) & $0(0)$ & $0(0)$ & $0(0)$ & $5(7.7)$ \\
\hline 31-60 days, n (\%) & $0(0)$ & $0(0)$ & $0(0)$ & $2(3.1)$ \\
\hline$>60$ days, $\mathrm{n}(\%)$ & $0(0)$ & $0(0)$ & $0(0)$ & $1(1.5)$ \\
\hline
\end{tabular}

[Controlled Substance Utilization Review and Evaluation System] system in the state of California ${ }^{7}$ ) when considering pain control management for a patient without a clear trend.

For providers who prescribe opioids at time of discharge, $56.9 \%$ report they provide detailed instructions for how patients can wean or taper off opioids. Few providers (6.1\%) prescribe alternative medications; those who do reported ginger, turmeric, berries, and marijuana.

Almost half of providers reported their hospitals have prescriptive opioid practice guidelines (47.0\%), whereas 33.3\% reported their hospitals did not have guidelines and $19.7 \%$ reported they were unsure. Most providers transition pain management to a patient's primary care provider at 1 month after discharge (47.0\%) or later (15.2\% between 2 and 3 months after discharge), although $22.7 \%$ reported they transition pain management to a patient's primary care provider within 2 weeks after discharge. For providers in practice for more than 5 years $(n=64), 71.9 \%$ reported they have decreased the strength and/or number of opioids prescribed since they began practicing medicine and similarly, 76.6\% reported they have increased the strength and/ or number of non-opioid pain medications prescribed. Thirteen $(20.3 \%)$ responded they have not changed either the strength or number of opioids or non-opioids prescribed.

\section{DISCUSSION}

Most providers (71.9\%) report they have decreased the strength/ number of opioids prescribed over their career. However, the mean number of opioid tablets typically prescribed was similar between scenarios (20-30 tablets), despite the predominant belief by participants that patients who undergo laparoscopic cholecystectomy should only have acute pain for 3 days or less.

Patients with high opioid use in the hospital, history of opioid use/abuse, or who live far from the provider may be prescribed more opioids at discharge. Although most providers $(78.8 \%)$ always or often ask patients about their previous experience with opioids and a majority (56.9\%) report they offer information for how patients can wean off opioids, fewer create

Table 4 If your patient who underwent an elective laparoscopic cholecystectomy was using opioid pain medication regularly prior to their operation, how would this change the opioid and non-opioid medications you would prescribe?

\begin{tabular}{|c|c|c|c|c|}
\hline & \multicolumn{2}{|l|}{ Opioids } & \multicolumn{2}{|c|}{ Non-opioids } \\
\hline & Increase & No change & Increase & No change \\
\hline $\begin{array}{l}\text { Number or strength of } \\
\text { medications, } \mathrm{n}(\%)\end{array}$ & $11(16.9)$ & $45(69.2)$ & $21(35.0)$ & $33(55.0)$ \\
\hline Dose of medications, $\mathrm{n}(\%)$ & $30(46.2)$ & $35(53.9)$ & $18(31.6)$ & $39(68.4)$ \\
\hline Number of tablets, n (\%) & $11(16.9)$ & $54(83.1)$ & $17(30.4)$ & $39(69.6)$ \\
\hline
\end{tabular}

pain contracts with patients. Hospital practice guidelines for prescribing opioids were also variable, and 19.7\% of respondents were unsure whether their hospitals had guidelines. These results suggest that although surgeons who participated in this survey have taken steps over recent years to reduce the amount of opioids they prescribe, tangible evidence-based solutions to guide provider practices are needed.

There is evidence that physicians are overprescribing opioid medications. In a study of almost 40000 opioid-naïve patients aged 66 years or older with major elective surgery between 2003 and 2010, almost half (49.2\%) were prescribed an opioid at time of discharge and $3.1 \%$ continued to receive opioids for more than 90 days after operation. ${ }^{8}$ Risk factors for opioid use 90 days after operation included younger age, lower household income, and use of specific drugs preoperatively (benzodiazepines, selective serotonin reuptake inhibitors, and ACE inhibitors). Patients

Table 5 What factors make you more likely to prescribe more or less opioids? Choose up to three (Bold indicates top three)

$\begin{array}{ll}\begin{array}{l}\text { Factors that make } \\ \text { you more likely to } \\ \text { prescribe more opioid } \\ \text { tablets or a higher } \\ \text { dose of opioids } \\ (n=139)\end{array} & \begin{array}{l}\text { Factors that make } \\ \text { prescribe less opioid } \\ \text { tablets or a lower } \\ \text { dose of opioids } \\ (n=172)\end{array} \\ n(\%) & n(\%) \\ 9(6.5) & 8(4.7)\end{array}$

None, I
amount

\begin{tabular}{lll}
$\begin{array}{l}\text { Anticipated delay in time to } \\
\text { follow-up }\end{array}$ & $10(7.2)$ & $1(0.6)$ \\
\hline Patient lives far away & $18(12.9)$ & $1(0.6)$ \\
Younger & $4(2.9)$ & $4(2.3)$ \\
\hline Older & N/A -not an option & $40(23.3)$ \\
\hline Frail & N/A -not an option & $42(24.4)$ \\
\hline Low body mass index & $0(0)$ & $13(7.6)$ \\
\hline High body mass index & $5(3.6)$ & $0(0)$ \\
\hline High opioid use in the hospital & $45(32.4)$ & $1(0.6)$ \\
\hline History of opioid use/abuse & $34(24.5)$ & $10(5.8)$ \\
\hline History of drug/alcohol abuse & $4(2.9)$ & $13(7.6)$ \\
\hline History of depression/anxiety & $2(1.4)$ & $11(6.4)$ \\
\hline History of other psychiatric & $0(0)$ & $9(5.2)$ \\
disorders & & $10(5.8)$ \\
\hline Patient request & $0(0)$ & N/A—not an option \\
\hline Other: injury pattern & $4(2.9)$ & $4(2.3)$ \\
\hline Other: low opioid use in hospital & N/A—not an option & $5(2.9)$ \\
\hline Other & $4(2.9)$ & \\
\hline
\end{tabular}


Table 6 Investigating history of opioid/narcotic use and creating pain contracts

\begin{tabular}{|c|c|c|c|c|c|}
\hline How often do you: & $\begin{array}{l}\text { Always } \\
(\%)\end{array}$ & Often $(\%)$ & $\begin{array}{l}\text { Sometimes } \\
(\%)\end{array}$ & Rarely (\%) & $\begin{array}{l}\text { Never } \\
(\%)\end{array}$ \\
\hline Ask patients about their previous experience with opioids (ie, if they have used or abused opioids)? ( $n=66)$ & $29(43.9)$ & $23(34.9)$ & $5(7.6)$ & $9(13.6)$ & $0(0)$ \\
\hline Create pain contracts with patients? $(n=66)$ & $3(4.5)$ & $1(1.5)$ & $14(21.2)$ & $38(57.6)$ & $10(15.2)$ \\
\hline $\begin{array}{l}\text { Use a prescription history database, such as the CURES } 2.0 \text { system in California, when considering the pain } \\
\text { control plan for a patient? ( } n=66)\end{array}$ & $14(21.2)$ & $11(16.7)$ & $16(24.2)$ & $15(22.7)$ & $10(15.2)$ \\
\hline
\end{tabular}

CURES, Controlled Substance Utilization Review and Evaluation System.

undergoing thoracic procedures were also at higher risk of opioid dependence.

Providers at Dartmouth Hitchcock Medical Center prescribed similar amounts of opioid medications at discharge as we found in our study. ${ }^{9}$ Hill et al reviewed 642 patients undergoing five outpatient procedures and found that only $28 \%$ of the prescribed pills were taken. They estimated that the number of pills required to meet the opioid needs of patients undergoing these operations was 5-15 (partial mastectomy 5; partial mastectomy with sentinel lymph node biopsy 10; laparoscopic cholecystectomy 15; laparoscopic inguinal hernia repair 15; and open inguinal hernia repair 15). Having an evidence-based understanding of the typical duration of pain and opioid requirements based on patient characteristics can help tailor postoperative pain regimens to patient needs, preventing overprescribing of opioids.

Trauma patients also receive moderately high rates of opioid medications at discharge. Among opioid-naive trauma patients who were beneficiaries of Military Health Insurance (military personnel and their dependents) who were treated between 2006 and 2013, over half (54.3\%) received an opioid prescription at discharge. ${ }^{10}$ Higher age, marriage, and higher Injury Severity Score were associated with higher likelihood of opioid prescription at discharge, whereas male sex and anxiety were associated with a decreased likelihood of opioid prescription at discharge. Although the authors argue these rates of opioid prescriptions correspond to the incidence of patients reporting moderate to severe pain after trauma in the literature, it is unclear how many patients who were prescribed opioids took them and how many prescriptions (or pills) were not needed.

Risk of postoperative chronic use of opioid medications includes male sex, older age, preoperative history of drug abuse, alcohol use, depression, benzodiazepine use, and antidepressant use. $^{511-13}$

\section{Limitations}

The primary limitation is the low response rate from members of AAST (40 of 1358 members, or $2.9 \%$ of the membership). These data are thus skewed towards beliefs and practices by respondents at a single institution in California. Data were also self-reported and actual prescription practices were not confirmed. Also, at some institutions (such as academic hospitals), resident physicians or other providers may prescribe more medications than attending surgeons; thus, the practices and beliefs of attending physicians may not always correlate to what is actually being prescribed.

\section{CONCLUSIONS}

In this survey, trauma and acute care surgeons and nurse practitioners report prescribing less opioid pain medications. However, most regularly prescribe 20-30 tablets of opioid medications and less than half of providers prescribe both opioid and non-opioid medications. More evidence-based studies are needed to better understand the appropriate amount of opioid and non-opioid pain medications (tailored to patients' injuries, operations, and personal characteristics) to ensure adequate pain control while mitigating the risk of opioid dependence.

Contributors All authors contributed to the concept, study design, article drafting, and critical revisions. JEA takes responsibility for data collection and analysis.

Funding The authors have not declared a specific grant for this research from any funding agency in the public, commercial or not-for-profit sectors.

Competing interests None declared.

Patient consent for publication Not required.

Ethics approval The study was approved by the UC Davis Institutional Review Board.

Provenance and peer review Not commissioned; externally peer reviewed.

Open access This is an open access article distributed in accordance with the Creative Commons Attribution Non Commercial (CC BY-NC 4.0) license, which permits others to distribute, remix, adapt, build upon this work non-commercially, and license their derivative works on different terms, provided the original work is properly cited, appropriate credit is given, any changes made indicated, and the use is non-commercial. See: http://creativecommons.org/licenses/by-nc/4.0/.

\section{REFERENCES}

1. Center for Disease Control and Prevention. Drug Overdose Death Data. https://www. cdc.gov/drugoverdose/data/statedeaths.html (Accessed September 30, 2018).

2. Center for Disease Control and Prevention. Prescription Opioid Data. https://www. cdc.gov/drugoverdose/data/prescribing.html (Accessed September 27, 2018).

3. Brummett CM, Waljee JF, Goesling J, Moser S, Lin P, Englesbe MJ, Bohnert ASB, Kheterpal S, Nallamothu BK. New persistent opioid use after minor and major surgical procedures in US adults. JAMA Surg 2017;152:e170504.

4. Jiang $X$, Orton M, Feng R, Hossain E, Malhotra NR, Zager EL, Liu R. Chronic opioid usage in surgical patients in a large academic center. Ann Surg 2017;265:722-7.

5. Sun EC, Darnall BD, Baker LC, Mackey S. Incidence of and risk factors for chronic opioid use among Opioid-Naive patients in the postoperative period. JAMA Intern Med 2016;176:1286-93.

6. Shah A, Hayes CJ, Martin BC. Characteristics of initial prescription episodes and likelihood of long-term opioid use - United States, 2006-2015. MMWR Morb Mortal Wkly Rep 2017;66:265-9.

7. Medical Board of California. CURES. http://www.mbc.ca.gov/Licensees/Prescribing/ CURES/ (Accessed 30 Sep 2018).

8. Clarke H, Soneji N, Ko DT, Yun L, Wijeysundera DN. Rates and risk factors for prolonged opioid use after major surgery: population based cohort study. BMJ 2014;348:g1251.

9. Hill MV, McMahon ML, Stucke RS, Barth RJ. Wide variation and excessive dosage of opioid prescriptions for common general surgical procedures. Ann Surg 2017;265:709-14

10. Chaudhary MA, Schoenfeld AJ, Harlow AF, Ranjit A, Scully R, Chowdhury R, Sharma M, Nitzschke S, Koehlmoos T, Haider AH, et al. Incidence and predictors of opioid prescription at discharge after traumatic injury. JAMA Surg 2017;152:930-6.

11. Carroll I, Barelka P, Wang CKM, Wang BM, Gillespie MJ, McCue R, Younger JW, Trafton J, Humphreys K, Goodman SB, et al. A pilot cohort study of the determinants of longitudinal opioid use after surgery. Anesth Analg 2012;115:1-702.

12. Helmerhorst GTT, Vranceanu A-M, Vrahas M, Smith M, Ring D. Risk factors for continued opioid use one to two months after surgery for musculoskeletal trauma. J Bone Joint Surg Am 2014;96:495-9.

13. Holman JE, Stoddard GJ, Higgins TF. Rates of prescription opiate use before and after injury in patients with orthopaedic trauma and the risk factors for prolonged opiate use. J Bone Joint Surg Am 2013;95:1075-80. 